\title{
Trends on epidemiological, virological, and clinical features among newly diagnosed HIV-1 persons in Northwest Spain over the last 10 years
}

\author{
B. Pernas, ${ }^{1}$ A. Mena, ${ }^{1}$ A. Cañizares,${ }^{2}$ M. Grandal,${ }^{1}$ A. Castro-Iglesias, ${ }^{1}$ S. \\ Pértega, ${ }^{3}$ J.D. Pedreira, ${ }^{1}$ and E. Poveda, ${ }^{1}$ \\ ${ }^{1}$ Division of Clinical Virology, INIBIC-Complejo Hospitalario Universitario de A Coruña (CHUAC), \\ SERGAS, Universidade da Coruña, A Coruña, Spain \\ ${ }^{2}$ Service of Microbiology, INIBIC-Complejo Hospitalario Universitario de A Coruña (CHUAC), SERGAS, \\ Universidade da Coruña, A Coruña, Spain \\ ${ }^{3}$ Clinical Epidemiology and Biostatistics Unit, INIBIC-Complejo Hospitalario Universitario de A Coruña \\ (CHUAC), SERGAS, Universidade da Coruña, A Coruña, Spain
}

\begin{abstract}
To describe temporal trend and characteristics of newly HIV-diagnosed patients in a medical care area in Northwest Spain over the last 10 years. All newly diagnosed patients for HIV-infection from 2004 to 2013 at a reference medical care area in Northwest of Spain were identified. Epidemiological, virological, immunological, and clinical data, as well as HIV genotype and drug resistance information were recorded. A total of 565 newly HIV-diagnosed patients were identified. The number of new cases increased in the last 5 years (66 cases/year). Overall, $53.1 \%$ had a median CD4 counts $<350$ cells $/ \mu 1$ and $33.6 \%$ had an AIDS defining criteria. Non-B variants were found in $34.4 \%$ of patients being subtype F $(25.8 \%)$ the most common non-B subtype. The rate of transmitted drug resistance (TDR) over the study period was $3.7 \%$, but a decreased to $2.6 \%$ was observed in the last 5 years. The most prevalent TDR mutations were: T215 revertants (1.5\%), K219QENR (1.2\%), for NRTIs; K103N (1.9\%), for NNRTIs; L90M (0.3\%), for PIs. Overall, 73.2\% of patients started antiretroviral treatment and $9.9 \%$ of patients died during follow-up. The number of newly HIV diagnosed patients increased since year 2009. There is a high prevalence of late diagnosis (53\%) and $33 \%$ had an AIDS defining criteria. Interestingly, the most prevalent non-B subtype in our population was $\mathrm{F}$ $(25.8 \%)$. These findings support the need to facilitate the access for HIV testing to reduce the rate of late HIV diagnosis, improve the clinical outcome and prevent HIV transmission.
\end{abstract}

Key words

Newly HIV-diagnoses; Late diagnosis; HIV-1 genetic subtype; Transmitted drug resistance 


\section{INTRODUCTION}

HIV infection continues to be an important health problem worldwide. It is estimated that more than 35 million people are living with HIV; more than 2 million new infections are recorded worldwide and 1.5 million people die each year from causes related to HIV infection [WHO/UNAIDS, 2013]. In Spain, a total of 25,731 new HIV patients were notified from 2003, with annual rates per 100,000 populations that vary from 9.8 in 2003 to 12.2 in 2010 [Ministry of Health, Spain, 2013]. With the introduction of highly active antiretroviral therapy (ART), HIV-1 infection is now manageable as a chronic disease in patients who have access to medication and who achieve durable virologic suppression [Palella et al., 1998].

It is estimated that in Europe, almost 30\% of HIV-infected persons still remain undiagnosed with an overall incidence of late presentation around 50\% of all HIV cases [Scognamiglio et al., 2013]. These high rates play an important role because late presentation of HIV infection is associated with shorter survival, slow and poor response to treatment, higher frequency of ART toxicity, increased healthcare costs and rates of HIV transmission [Moreno et al., 2010; Sabin et al., 2010; Camoni et al., 2013].

Moreover, other factors may also have an important role in the management of HIV infection. This is the case of the extraordinary genetic variability which characterizes HIV infection with a potential impact on disease progression, diagnosis, therapy, and epidemiology [De Felipe et al., 2011]. HIV epidemic is characterized by a high genotypic diversity and several HIV subtypes and circulating recombinant forms (CRFs) have been described [Walèria-Aleixo et al., 2008; Luft et al., 2011; Schrrer et al., 2011]. HIV-1 subtype B is predominant in North America and Western Europe, including Spain, although is responsible for only $10 \%$ of global infections [Luft et al., 2011; Scherrer et al., 2011]. However, the prevalence of HIV-subtypes varies greatly depending on the geographic region, partially because migration produced in the last decade has contributed to the current spread of non-B subtypes in developed countries [De Felipe et al., 2011; Luft et al., 2011]. Although the impact of drug resistance mutations on ART management have been well characterized in HIV-1 subtype B infected patients in the developed world, less data are available regard non-B subtypes [Johnson et al., 2008]. Thus, resistance against antiretroviral drugs in previously untreated HIV patients is of growing relevance. It has been hypothesized that a wide use of antiretroviral drugs could result in an increase in drug-resistant virus transmission and more generally in the prevalence of resistance variants [Sagir et al., 2007]. Overall, the prevalence of TDR varies between 9-24\% in Europe and 3-15\% in Spain, with the highest TDR rates for both nucleoside reverse transcriptase inhibitors (NRTIs) and non-nucleoside reverse transcriptase inhibitors (NNRTIs) followed by protease inhibitors (PIs) [Sagir et al., 2007; Bracciale et al. 2009; Wittkop et al., 2011; Monge et al., 2012, 2014].

Therefore, to establish the best strategies for HIV diagnosis, prevention and treatment it is important to get a deep knowledge of the characteristics of newly HIV infections in our medical setting. Thus, the objective of this study was to analyze the clinical, virological, and immunological characteristics in a cohort of newly HIV-1 diagnosed patients in the last 10 years. The prevalence of HIV-1 subtypes, drug resistance mutations associated to protease and reverse transcriptase inhibitors and factors associated to clinical outcome (response to ART and mortality) were also evaluated. 


\section{METHODS}

All newly diagnosed patients for HIV infection from January 2004 to December 2013 at the medical area of A Coruña, in the northwest of Spain, were recorded. This reference area attends more than 500,000 citizens. Factors included in our analysis were epidemiological and clinical characteristics at diagnosis, immunological and virological status, HIV-1 subtype, and TDR. Characteristics of ART and mortality were also evaluated.

Late diagnosis was defined as CD4 count $<350$ cells $/ \mathrm{mm}^{3}$ at HIV diagnosis and/or an AIDSdefining event at presentation. The presence of AIDS was defined according to the Centers for Diseases Control and Prevention (CDC) as the presence of CD4 count $<200$ cells $/ \mathrm{mm}^{3}$ and/or clinic category $\mathrm{C}$.

Resistance testing was performed following the recommendations of HIV treatment guidelines in force at the moment of starting ART. Both HIV protease and reverse transcriptase were amplified from plasma samples using TruGene HIV-1 Genotyping Test (Siemens). FASTA format sequences from the HIV protease and reverse transcriptase were obtained and HIV-1 subtypes were assigned using the freely available algorithm from Stanford University Drug Resistance Database (http://hivdb.stanford.edu/hiv/).

The presence of resistance-associated mutations was evaluated following the Antiretroviral Resistance Guidelines, from the Spanish AIDS Research Network, updated in 2013 [De Mendoza et al., 2009a].

This research protocol was approved by the regional ethics committee ("Comité Ético de Investigación Clínica de Galicia," register code 2013/247).

The statistical analysis was performed using the Statistical Package for the Social Sciences software (SPSS 19.0, Chicago, IL). Categorical variables are presented as number of cases or percentage and were compared by the $\chi^{2}$ test or Fisher's exact test, when appropriate. Continuous variables are expressed as median (interquartile range, IQR) and compared by non-parametric Mann-Whitney and Kruskal-Wallis test, when appropriate. Multivariate logistic regression analysis was used to identify factors independently associated with response to ART. Epidemiological characteristics, HIV status at diagnosis and ART regimen were included in univariate analysis but only covariates statistically associated with response to ART in univariate analysis were included in multivariate logistic regression. Cox regression was used to identify factors associated with mortality. Epidemiological characteristics, HIV status at diagnosis and use of ART were included in univariate analysis and covariates statistically associated with mortality in univariate analysis were included in Cox regression. A $P$-value of $<0.05$ was considered statistically significant.

\section{RESULTS}

\section{Epidemiologic Characteristics}

A total of 565 newly HIV diagnosed patients were identified. Table I describes epidemiological, immunological, virological, and clinical characteristics of the study population at the diagnosis time. The number of new HIV-diagnoses increased significantly from 47 cases/year in period 2004-2008 to 66 cases/year in period 2009-2013 $(P<0.001)$. The distribution of new diagnoses per year is shown in Figure 1. The changes in the routes of transmission in the study period are shown in Figure 2. Interestingly, new HIV infections in men who have sex with men (MSM) have showed a great increase in the last 5 years, while a remarkable decrease among heterosexual and intravenous drug users (IDU) is observed since 2011 and 2006, respectively. 
When comparing 5-year periods 2004-2008 and 2009-2013, a significant decreasing in new HIV infections among heterosexual (50.9\% vs. $37.4 \%)$ and IDU populations (19\% vs. $8.3 \%)$ and an increasing among MSM $(30.1 \%$ vs. $54 \%)(P<0.001)$ was observed.

Table I. Baseline Characteristics of the Study Population

\begin{tabular}{|c|c|}
\hline Variables & $\mathrm{N}=565$ \\
\hline \multicolumn{2}{|l|}{ Demographic-epidemiological } \\
\hline Male & $468(83 \%)$ \\
\hline Age (years) & $37(30-44)$ \\
\hline \multicolumn{2}{|l|}{ Routes of HIV transmission } \\
\hline Heterosexual & $228(43.2 \%)$ \\
\hline MSM & $206(39 \%)$ \\
\hline IDU & $93(17.6 \%)$ \\
\hline Vertical transmission & $1(0.2 \%)$ \\
\hline \multicolumn{2}{|l|}{ Nationality } \\
\hline Spanish & $475(79 \%)$ \\
\hline European & $18(3.2 \%)$ \\
\hline South-American & $84(14.9 \%)$ \\
\hline North-American & $2(0.4 \%)$ \\
\hline Asian & $1(0.2 \%)$ \\
\hline African & $13(2.3 \%)$ \\
\hline \multicolumn{2}{|l|}{ HIV status } \\
\hline Median CD4 (cells/ $\mu 1)$ & $344(128-550)$ \\
\hline $\mathrm{CD} 4$ count $<350$ cells $/ \mu 1$ & $295(53.1 \%)$ \\
\hline Median RNA-HIV log (copies/ml) & $4.98(4.4-5.4)$ \\
\hline \multicolumn{2}{|l|}{ Clinical presentation at diagnosis } \\
\hline No symptoms & $363(66.4 \%)$ \\
\hline Primary infection & $36(6.5 \%)$ \\
\hline Non-AIDS defining disease (clinical category B) & $44(8 \%)$ \\
\hline AIDS defining disease (clinical category $\mathrm{C}$ ) & $105(19.1 \%)$ \\
\hline \multicolumn{2}{|l|}{ Co-infections } \\
\hline HBsAg positive & $12(2.1 \%)$ \\
\hline Anti-HCV positive & $112(19.9 \%)$ \\
\hline Sexual transmitted diseases & $39(9.1 \%)$ \\
\hline
\end{tabular}

Data are n (\%) or median (interquartile range). 


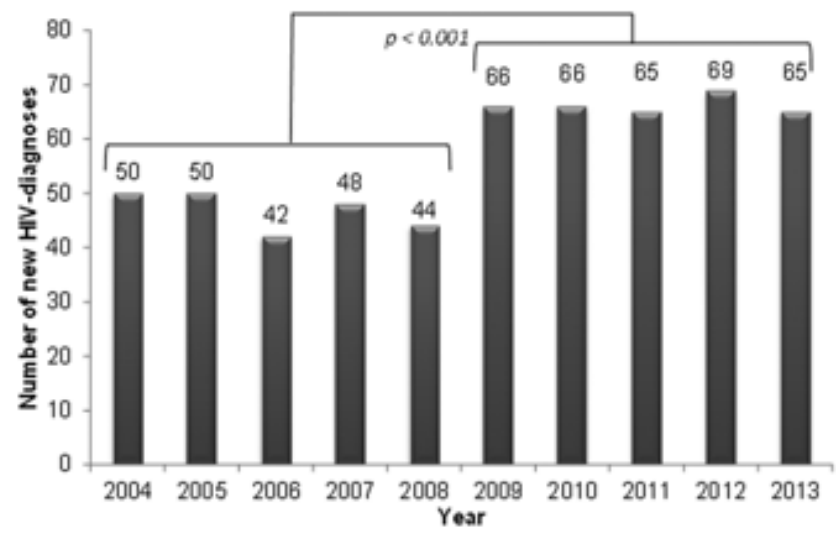

Figure 1. Distribution of newly HIV diagnosed patients per year of follow-up.

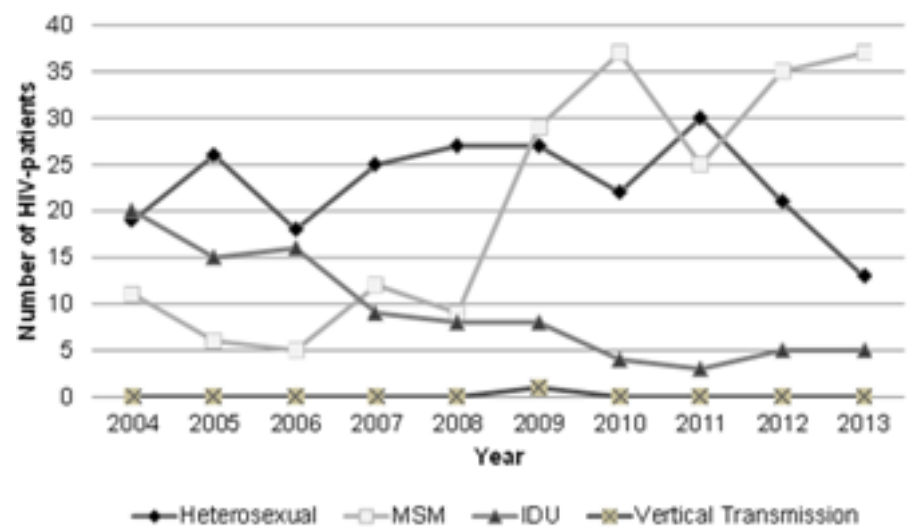

Figure 2. Distribution of new HIV-diagnoses per routes of transmission and year of diagnosis.

\section{HIV Clinical Status}

The median CD4 cell count and plasma HIV-RNA level at the time of HIV-diagnosis were 344 (128-550) cells/ $\mu \mathrm{l}$ and 4.98 (4.4-5.4) $\log$ copies/ml, respectively. Overall, 295 patients (53.1\%) of the new HIV infections were late diagnoses and 183 patients $(33.6 \%)$ of newly-diagnosed HIV patients had an AIDS defining criteria. The prevalence of late diagnosis was stable comparing 5year periods 2004-2008 and 2009-2013 (56.1\% vs. 50.9\%, respectively, $P=0.229$ ) as well as the percentage of patients with AIDS (35.4\% vs. $32.4 \%$, respectively, $P=0.467)$. The most prevalent AIDS defining diseases at diagnosis were: Pneumocystis jiroveci pneumonia (41.3\%), tuberculosis $(21.1 \%)$, lymphoma (5.8\%), toxoplasmosis $(4.8 \%)$, HIV encephalopathy or progressive multifocal leukoencephalopathy $(3.8 \%)$, wasting syndrome $(3.8 \%)$, esophageal candidiasis $(2.9 \%)$, atypical mycobacteria infection $(1 \%)$, other syndromes $(15.5 \%)$. 


\section{HIV Genotypic Subtypes}

The HIV subtype was available for 314 patients (55.6\%), of whom 108 subjects $(34.4 \%)$ were infected with HIV-1 non-B subtypes. Significance increased in the prevalence of non-B subtypes within the last 5 years from $27.8 \%$ in 2009 to $41.3 \%$ in 2013 has been observed. Subtype F was the most prevalent non-B subtype (25.8\%). The HIV subtypes distribution in the study population is shown in Figure 3. Of note, MSM transmission was responsible of $79.2 \%$ of newly HIV-patients with subtype $\mathrm{F}$ while subtype $\mathrm{B}$ and other non-B/F variants were transmitted by heterosexual (47.3\% and 54.2\%, respectively) and MSM route (47.3\% and $41.7 \%$, respectively). Among the IDU population, new HIV infections corresponded in a $10.1 \%$ to subtype B, $1.3 \%$ to subtype $\mathrm{F}$ and $4.2 \%$ to other HIV-variants. Significant differences in the route of transmission between HIVsubtypes were observed $(P<0.001)$.

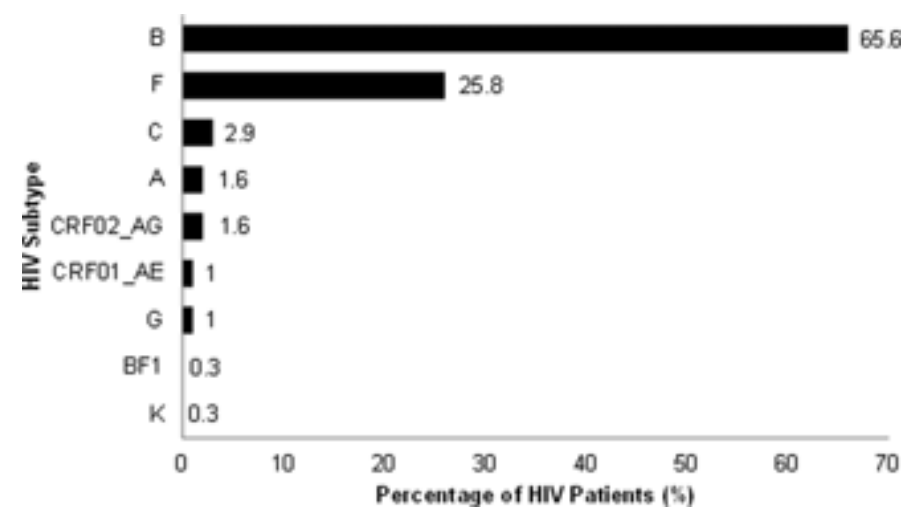

Figure 3 Distribution of HIV-1 subtypes and CRFs.

\section{Transmitted Drug Resistance Mutations}

Genotypic resistance testing was performed in 323 patients (58.1\%). Table II shows the prevalence of mutations according to the list of TDR identified for treatment-naïve HIV infected patients. The overall prevalence of TDR in this population was $3.7 \%$. The most prevalent TDR mutations were: T215 revertants (1.5\%), K219QENR (1.2\%), for NRTIs; K103N (1.9\%), for NNRTIs; L90M $(0.3 \%)$, for PIs. Regarding to antiretroviral drug families, the prevalence of TDR mutations was $2.5 \%, 2.5 \%$ and $0.3 \%$ for NRTIs, NNRTIs and PIs, respectively. Overall, three patients $(0.9 \%)$ had TDR mutations only for NRTIs, three patients $(0.9 \%)$ for NNRTIs, 1 patient $(0.3 \%)$ for PIs and five patients $(1.6 \%)$ had TDR mutations for both NRTIs and NNRTIs. Figure 4 shows the overall prevalence of TDR and by drug class between 2004-2008 and 2009-2013. Decreasing rates of TDR was observed from $10.2 \%$ (2004-2008) to $2.6 \%$ (2009-2013) in the last 5 years $(P=0.023)$. However, there were no significant differences in the prevalence of mutations specifically associated with NRTIs, NNRTIs or PIs resistance comparing the two 5-year periods but there was a trend to decreasing rates in the last 5 years. Within the last 5 years (2009-2013), the annual prevalence of transmitted drug resistance (NRTIs, NNRTIs, and PIs mutations) was less than 5\% and no clear downward trend was observed in this period. 
Table II. Prevalence of TDR Mutations in Newly Diagnosed HIV-Infected Patients

\begin{tabular}{|c|c|c|c|c|c|}
\hline \multicolumn{2}{|c|}{ NRTIs mutations, $\mathrm{n}(\%)$} & \multicolumn{2}{|c|}{ NNRTIs mutations, $\mathrm{n}(\%)$} & \multicolumn{2}{|c|}{ PIs mutations, $\mathrm{n}(\%)$} \\
\hline M41L & $1(0.3)$ & L100I & $0(0)$ & L23I & $0(0)$ \\
\hline K65R & $1(0.3)$ & K101EP & $1(0.3)$ & L24I & $0(0)$ \\
\hline D67EGN & $2(0.6)$ & K103NS & $6(1.9)$ & D30N & $0(0)$ \\
\hline T69D & $1(0.3)$ & V106AM & $1(0.6)$ & V32I & $0(0)$ \\
\hline K70ER & $0(0)$ & V179F & $0(0)$ & M46IL & $0(0)$ \\
\hline L74IV & $0(0)$ & Y181CIV & $0(0)$ & I47AV & $0(0)$ \\
\hline V75AMTS & $0(0)$ & Y188CHL & $3(0.9)$ & G48MV & $0(0)$ \\
\hline F77L & $0(0)$ & G190AES & $0(0)$ & I50LV & $0(0)$ \\
\hline $\mathrm{Y} 115 \mathrm{~F}$ & $1(0.3)$ & $\mathrm{P} 225 \mathrm{H}$ & $0(0)$ & F53LY & $0(0)$ \\
\hline F116Y & $0(0)$ & M230IL & $0(0)$ & I54ALMSTV & $0(0)$ \\
\hline Q151M & $0(0)$ & & & G73ACST & $0(0)$ \\
\hline M184IV & $1(0.3)$ & & & L76V & $0(0)$ \\
\hline L210W & $0(0)$ & & & V82ACFLMST & $0(0)$ \\
\hline $\mathrm{T} 215 \mathrm{REV}^{\mathrm{a}}$ & $5(1.5)$ & & & $\mathrm{N} 83 \mathrm{D}$ & $0(0)$ \\
\hline $\mathrm{T} 215 \mathrm{YF}$ & $0(0)$ & & & I84ACV & $0(0)$ \\
\hline \multirow[t]{3}{*}{ K219ENQR } & $4(1.2)$ & & & $\mathrm{I} 85 \mathrm{~V}$ & $0(0)$ \\
\hline & & & & N88DS & $0(0)$ \\
\hline & & & & L90M & $1(0.3)$ \\
\hline
\end{tabular}

\section{${ }^{a} \mathrm{REV}: \mathrm{C} / \mathrm{D} / \mathrm{E} / \mathrm{I} / \mathrm{N} / \mathrm{S} / \mathrm{V}$}

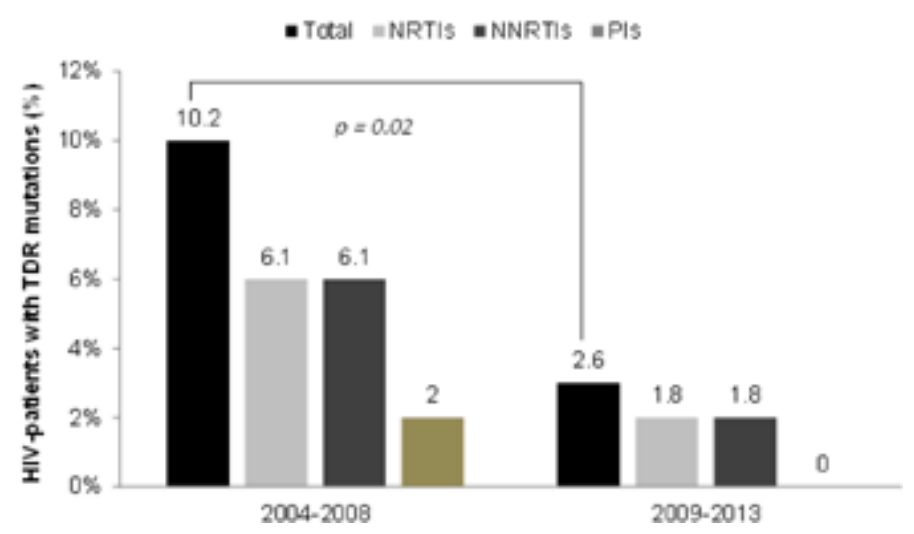

Figure 4. Rates of TDR mutations in periods 2004-2008 and 2009-2013. 


\section{Antiretroviral Treatment and Mortality}

Overall, 413 patients $(73.2 \%)$ started ART. The median of CD4 count at the beginning of ART was 207 (76-317). The regimen of ART was based on: 2 NRTIs + 1 NNRTIs (45.7\%); 2 NRTIs + 1 PIs (46.7\%); 2 NRTIs + integrase inhibitor $(5.2 \%)$, and other regimens $(2.4 \%)$. The median time from HIV diagnosis to ART initiation was 3 (1-17) months. Overall, after 48 weeks of ART, $65 \%$ achieved undetectable viremia (HIV-RNA $<20$ copies $/ \mathrm{ml}$ ). In multivariate analysis, after adjusting for sex, the presence of HIV viral load $<100,000 \mathrm{copies} / \mathrm{ml}$ at the time of diagnosis (OR 2.3 [1.3-3.9], $P=0.001$ ) and heterosexual transmission (OR 2.5 [1.4-4.6], $P=0.007$ ) were significantly associated with virological response to ART; while PIs regimen was associated with lower virological response (OR $0.5[0.3-0.8], P=0.005)$.

During follow-up, 56 patients $(9.9 \%)$ died, and the death occurred during hospitalization at HIV-diagnosis in 18 patients $(3.2 \%)$. The median time from HIV diagnosis to death was 26 (6-42 months). In multivariate analysis, after adjusting for sex, age (HR 1.04 [1.019-1.065], $P<0.001)$ and the presence of an AIDS-defining disease at the time of diagnosis (HR 7.1 [3.5-14.3], $P<0.001)$ were significant associated with mortality; regarding the use of ART and mortality, to achieve undetectable viremia (HIV-RNA $<20$ copies/ml) was significant associated with a lower risk of mortality (HR $0.04[0.02-0.1], P<0.001$ ).

\section{DISCUSSION}

This study evaluates the characteristics of a large cohort of newly HIV diagnosed patients in Northwest of Spain in the last 10 years. A significant increase in the number of new HIV diagnosed patients was observed, from 47 cases/year in period 2004-2008 to 66 cases/year in the last 5 years. HIV epidemic affects mainly young (median age of 37 years) male (83\%) being sexual transmission the main route of infection (82\%). In the last 10 years, intravenous drug users have become a secondary route of transmission while a significant predominance of HIV infection among MSM has been observed. The increase in new HIV-infections observed in our population could be related to the high prevalence of MSM since year 2009, similarly to the significant increase on the HIV prevalence among MSM described in Europe and North America [Van Griensven et al., 2009; WHO/UNAIDS, 2013]. Moreover, high-risk sexual behavior among MSM described in recent years, as well as MSM are more likely to get tested for HIV might explain the increase in new HIV-infections in the last 5 years [Camoni et al., 2013; Fernández-Dávila et al., 2013].

High rates of late HIV diagnosis was observed in our study population since half of them (53.1\%) had CD4 counts $<350$ cells/ $\mu$ l and $33.6 \%$ had an AIDS defining criteria at the time of diagnosis. Reducing late HIV diagnosis is considered a public health priority and continues to be a great challenge in most countries [Phillips et al., 2007; Palacios et al., 2008; Dolpech et al., 2013; Shen et al., 2013]. To gain this goal, the US CDC and the US Preventive Services Task Force (USPSTF) newly recommended one-time HIV testing for persons aged 15-65 at least once as part of routine health care [Branson et al., 2006; Moyer, 2013]. In Spain, HIV testing is generally performed in case of risk behavior or clinical suspicion, but is not incorporated as a routine screening. The high proportion of late presenters at HIV diagnosis observed in our study is similar to that reported in other European countries and in Spain [European Centre for Disease Prevention and Control, 2010; Palacios et al., 2008]. Of note, the rate of late HIV diagnosis (CD4 counts $<350$ cells $/ \mu \mathrm{l}$ ) and AIDS events was stable during all the study period. Therefore, it is critical to identify the characteristics of new HIV infections to establish optimal strategies for prevention and earlier HIV diagnosis [Camoni et al., 2013; Loconsole et al., 2013]. 
The identification of HIV-1 subtypes allows us to know the dynamics of HIV molecular epidemiology and different transmission or disease progression rates have been suggested [Zhang et al., 2010; Hemelaar et al., 2011]. Broad distribution of HIV-1 subtypes worldwide has been stable over time, with a prevalence for subtype B of more than $90 \%$ in Western Europe and the United States [Hemelaar et al., 2011; Luft et al., 2011]. However, the prevalence of non-B subtypes in Europe has increased during the last two decades and is mainly related to population movements. Although non-B subtypes were more common in people of non-Caucasian origin, their estimated prevalence in some European countries is more than $15 \%$ in Caucasians; similarly, in native Spaniards, the rate of non-B subtypes increased from $1.5 \%$ in $2000-2002$ to $11 \%$ in 2007-2010 [Bracciale et al., 2009; Treviño et al., 2011; Monge et al., 2012; Abecasis et al., 2013; Chaix et al., 2013].

The prevalence of non-B subtypes observed in our population (34\%) is much higher than the prevalence described in other Spanish cohorts as the Spanish AIDS Research Network CohortCoRIS (15.9\%) and with a HIV subtypes distribution also different. While the rates of CRFs account for almost $10 \%$ of all HIV infections in Spain, being CRF02_AG the most common non-B variant with a prevalence of $40 \%$ in Madrid [De Mendoza et al., 2009b; Treviño et al., 2011; Monge et al., 2012], the prevalence of CRFs in our population is much lower (3\%). Instead, subtype $\mathrm{F}$, that causes less than $1 \%$ of infections worldwide and $1.6 \%$ of newly HIV-diagnoses in CoRIS, affects one in four of the newly HIV-diagnosed patients in our study [Hemelaar et al., 2011; Luft et al., 2011; Monge et al., 2012]. The prevalence reported for subtype F varies between different geographic regions and overall is less than $5 \%$ but there are some exceptions. In Brazil, subtype F accounts for approximately $10-20 \%$ of non-B virus infection [Dias et al., 2009; Hemelaar et al., 2011]. Moreover, Romania has the highest prevalence described $(>70 \%)$ due to parenteral transmission in children in the late 1980s [Apetrei et al., 1998]. This association with demographic parameters suggests highly compartmentalized epidemics, determined by social and behavioral characteristics of the patients [Abecasis et al., 2013].

Observational evidence suggests that non-B subtypes are more able to transmit by the heterosexual route [Yirrell et al., 2008; Lai et al., 2012]. In fact, it has been recently described the spread of subtype $\mathrm{F}$ among Italian heterosexual men and up to $68 \%$ of the subtype F Brazilian patients were women being infected by heterosexual route [Monteiro et al., 2009; Lai et al., 2012]. However, subtype $\mathrm{F}$ is mainly transmitted by homosexual route in our study (79.2\%). Indeed, a rapid expansion of subtype $\mathrm{F}$ among MSM in Galicia was reported in HIV newly diagnosed patients during 2010-2011 and the phylogenetic analyses traced the ancestry of this cluster in Brazil, where the prevalence of subtype $F$ is also high [Thomson et al., 2012]. The recognition of a high prevalence of subtype $\mathrm{F}$ in our population might be an important issue since more rapid disease progression, lower genetic barrier to drug resistance and different response to antiretroviral therapy among non-B subtypes has been described [Yirrell et al., 2008; Chaix et al., 2013; Pernas et al., 2014].

HIV treatment guidelines recommend performing an HIV drug resistance testing for all subjects beginning treatment [EACS, 2013; DHHS 2014]. Transmission of drug-resistant HIV variants is well documented and is associated with suboptimal virologic response to first-line antiretroviral treatment, limiting the therapeutic options [Sagir et al., 2007; Bracciale et al., 2009]. Overall, the prevalence of TDR varies between 9-24\% in Europe and 3-15\% in Spain [Wittkop et al., 2011; Monge et al., 2012, 2014]. While a stable or declining prevalence of TDR was detected in some studies, others showed an increase in TDR prevalence [Sagir et al., 2007; Monge et al., 2012; Rodriguez-Rodrigues et al., 2013]. Overall, a significant decrease in TDR was observed from $10.2 \%$ at period $2004-2008$ to $2.6 \%$ at period 2009-2013.

In Spain, the TDR rate for NNRTIs has decreased from 5.2\% in 2007 to $2.8 \%$ in 2011 in naïve patients, but not for TDR associated with both NRTIs and PIs [Monge et al., 2012, 2014]. In our population, during the last 5 years it has been observed a decrease in the rates of TDR for NRTIs (6.1\% in 2004-2008 to $1.8 \%$ in 2009-2013), NNRTIs (6.1-1.8\%) and PIs (2-0\%) (Fig. 4). 
Moreover, in the CoRIS cohort, patients infected by non-B subtypes were at $73 \%$ of lower risk of having resistance to the NRTIs class [Walèria-Aleixo et al., 2008; Monge et al., 2012]. It has been proposed that changing features in the HIV-1 epidemic in European countries, characterized by a significant increase in non-B subtypes from populations migrating from countries with more limited access to ART, may partially justify the finding of a reduced prevalence of some TDR during the last years [Bracciale et al., 2009; De Mendoza et al., 2009b].

This low prevalence of TDR may influences treatment and diagnostic recommendations in the near future. In fact, some experts have suggested that might not be necessary to perform a baseline PIs resistance test, and only evaluate the presence of TDR for NNRTIs could be more costeffective in Spain [Monge et al., 2012, 2014] given the cost-benefit for performing genotypic studies in naive patients have been established for a TDR prevalence above 5\% [Sax et al., 2005]. This could be an interesting approach in our population because the global prevalence of TDR is $3.7 \%$ with a significant decrease in the last 5 years with a trend toward decreasing rates of NRTIs, NNRTIs, and PIs resistance.

Although some of our results are similar to those described in other studies, specific characteristics of our population, as the high prevalence of subtype F, could not be extrapolated to other regions in Spanish or European countries. These different features may have important implications in our daily clinical practice for the management of HIV-infected patients. One of the limitations of our study is the lack of the protease and reverse transcriptase sequences for all the study population and therefore the impossibility to determine the HIV subtype, particularly in the period 2004-2008 when to perform a genotypic HIV resistance test prior ART initiation was not mandatory [Vandamme et al., 2004; Recommendations from GESIDA, 2007].

In summary, new HIV infections increased in the last 5 years in the Northwest of Spain with a high prevalence of late diagnosis and AIDS events. These data highlights the need for a more active HIV testing in our population to promote early HIV diagnosis. Moreover, there is a high prevalence of subtype $\mathrm{F}$ in newly HIV diagnosed patients, being MSM the main route of transmission. These findings might be highly relevant for the clinical management of these patients and to establish the most optimal strategies for prevention and diagnosis.

\section{ACKNOWLEDGMENTS}

This work was supported in part by grants from Fondo de Investigación Sanitaria (CP08/00214, PI10/02166, CM13/00328, PI13/02266), and Fundación Profesor Novoa Santos, A Coruña. We would like to thank Biobank of A Coruña (SERGAS) for providing us the technical, ethical, and legal advice necessary for the development of our research.

\section{REFERENCES}

Abecasis AB, Wensing AM, Paraskevis D, Vercauteren J, Theys K, Van der Vijver DA, Albert J, Asjö B, Balotta C, Beshkov D, Camacho RJ, Clotet B, De Gascun C, Griskevicius A, Grossman Z, Hamouda O, Horvan A, Kolupajeve T, Korn K, Kostrikis LG, Kücherer C, Liitsola K, Linka M, Nielsen C, Otelea D, Paredes R, Poljak M, Puchhammer-Stöckl E, Schmit JC, Sönnerborg A, Stanekova D, Stanojevic M, Struck D, Boucher CA, Vandamme AM. 2013. HIV-1 subtype distribution and its demographic determinants in newly diagnosed patients in Europe suggest highly compartmentalized epidemics. Retrovirology 10:7.

Apetrei C, Necula A, Holm-Hansen C, Loussert-Ajaka I, Pandrea I, Cozmei C, Streinu-Cercer A, Pascu FR, Negut E, Molnar G, Duca M, Pecec M, Brun-Vézinet F, Simon F. 1998. HIV diversity in Romania. AIDS 12:1079-1085.

Bracciale L, Colafigli M, Zazzi M, Corsi P, Meraviglia P, Micheli V, Maserati R, Gianotti N, Penco G, Setti M, Di Giambenedetto S, Butini L, Vivarelli A, Trezzi M, De Luca A. 2009. Prevalence of transmitted HIV-1 drug resistance in HIV-1 infected patients in Italy: Evolution over 12 years and predictors. J Antimicrob Chemother 64:607-615. 
Branson BM, Handsfield HH, Lampe MA, Janssen RS, Taylor AW, Lyss SB, Clark JE, Centers for Disease Control and Prevention (CDC). 2006. Revised recommendations for HIV testing of adults, adolescents, and pregnant women in health-care settings. MMWR Recomm Rep 55:1-17.

Camoni L, Raimondo M, Regine V, Salfa MC, Suligoi B, regional representatives of the HIV Surveillance System. 2013. Late presenters among persons with a new HIV diagnosis in Italy, 2010-2011. BMC Public Health 13:281.

Chaix ML, Seng R, Frange P, Tran L, Avettand-Fenoël V, Ghosn J, Reynes J, Yazdanpanah Y, Raffi F, Goujard C, Rouzioux C, Meyer L, ANRS PRIMO Cohort Study Group. 2013. Increasing HIV-1 non-B subtype primary infections in patients in France and effect of HIV subtypes on virological and immunological responses to combined antiretroviral therapy. Clin Infect Dis 56:880-887.

De Felipe B, Pérez-Romero P, Abad-Fernández M, Fernandez-Cuenca F, Martínez-Fernandez FJ, Trastoy M, Mata R, del C, López-Cortés LF, Leal M, Viciana P, Vallejo A. 2011. Prevalence and resistance mutations of non-B HIV subtypes among immigrants in southern Spain along the decade 2000-2010. Virol J 8:416.

De Mendoza C, Anta L, García F, Pérez-Elías MJ, Gutiérrez F, Llibre JM, Menéndez-Arias L, Dalmau D, Soriano V. 2009a. HIV-1 genotypic drug resistance interpretation rules-2009 Spanish Guidelines. AIDS Rev 11:39-351.

De Mendoza C, Garrido C, Poveda E, Corral A, Zahonero N, Treviño A, Anta L, Soriano V. 2009b. Changes in drug resistance patterns following the introduction of HIV type 1 non-B subtypes in Spain. AIDS Res Hum Retroviruses 25:967-972.

PHHS. 2014. Panel on antiretroviral guidelines for adults and adolescents. Guidelines for the use of antiretroviral agents in HIV-1 infected adults and adolescents. Department of Health and Human Services. Available at http://aidsinfo.niv.gov/ContentFiles/AdultandAdolescentGL.pdf.

Dias CF, Nunes CC, Freitas IO, Lamego IS, Oliveira IM, Gilli S, Rodrigues R, Brigido LF. 2009. High prevalence and association of HIV-1 non-B subtype with specific sexual transmission risk among antiretroviral naïve patients in Porto Alegre, Brazil. Rev Inst med Trop S Paulo 51:191-196.

Dolpech V, Brown AE, Croxford S, Chau C, Polavarapu V, Cooper N, Rooney G, Yin Z. 2013. Quality of HIV care in the United Kingdom: Key indicators for the first 12 months from HIV diagnosis. HIV Med 14:19-24.

EACS. 2013. European AIDS Clinical Society. Guidelines version 7.0 October 2013. Available at http://www.eacsociety.org/Portals/0/Guidelines_Online_131014.pdf.

European Centre for Disease Prevention and Control. 2010. European Centre for Disease Prevention and Control/WHO Regional Office for Europe: HIV/AIDS surveillance in Europe 2009. Stockholm: European Centre for Disease Prevention and Control. 2010.

Fernández-Dávila P, Folch C, Ferrer L, Soriano R, Diez M, Casabona J. 2013. Who are the men who have sex with men in Spain that have never been tested for HIV? HIV Med 14:44-48.

Hemelaar J, Gouws E, Ghys PD, Osmanow S, WHO-UNAIDS Network for HIV Isolation and Characterization. 2011. Global trends in molecular epidemiology of HIV-1 during 2000-2007. AIDS 25:679-689.

Johnson VA, Brun-Vezinet F, Clotet B, Gunthard HF, Kuritzkes DR, Pillay D, Schapiro JM, Richman DD, International AIDS Society-USA Drug Resistance Mutations Group. 2008. Update of the Drug Resistance Mutations in HIV-1. Top HIV Med 16:138-145.

Lai A, Simonetti F, Zehender G, De Luca A, Micheli V, Meraviglia P, Corsi P, Bangarelli P, Almi P, Zoncada A, Paolucci S, Gonnelli A, Colao G, Tacconi D, Franzetti M, Ciccozzi M, Zazzi M, Balotta C. 2012. HIV-1 subtype F1 epidemiological networks among Italian heterosexual males are associated with introduction events from South America. PLoS ONE 7:e42223.

Loconsole D, Procacci R, Sallustio A, Quarto M, Germinario C, Chironna M, HIV Regional Coordinators 2013. Surveillance of new HIV infections/diagnoses in Puglia Region (South Italy), years 2007-2011. Ann Ig 5:291-298.

Luft LM, Gill MJ, Church DL. 2011. HIV-1 viral diversity and its implications for viral load testing: Review of current platforms. Int J Infect Dis 15:e661-e670.

Ministry of Health, Social Services and Equality. 2013. HIV/AIDS surveinllance, Spain. Update June 30th 2013. Sistema de información sobre nuevos diagnósticos de VIH. Registro Nacional de casos de SIDA.

Monge S, Guillot V, Alvarez M, Peña A, Viciana P, García-Bujalance S, Pérez-Elías MJ, Iribarren JA, Gutierrez F, Itziar Casado M, García M, CoRIS. 2012. Analysis of transmitted drug resistance in Spain in the years 2007-2010 documents decline in mutations to the non-nucleoside drug class. Clin Microbiol Infect 18:E485-E490.

Monge S, Guillot V, Alvarez M, Chueca N, Stella N, Peña A, Delgado R, Córdoba J, Aguilera A, Vidal C, García F, CoRIS. 2014. Clinically relevant transmitted drug resistance to first line antiretroviral drugs and implications for recommendations. PLoS ONE 9:e90710.

Monteiro JP, Alcantara LC, De Oliveira AM. 2009. Genetic variability of human immunodeficiency virus-1 in Bahia State, Northeast, Brazil: High diversity of HIV genotypes. J Med Virol 81:391-399. 
Moreno S, Mocroft A, D'amino A. 2010. Medical and societal consequences of late presentation. Antivir Ther 15:9-15.

Moyer VA, U. S. Preventive Services Task Force. 2013. Screening for HIV: U.S. Preventive Services Task Force Recommendation Statement. Ann Intern Med 159:51-60.

Palacios R, Viciana I, Pérez de Pedro I, de la Torre I, Ropero J, Fernández F, Salgado S, Roldán F, de Dios J, Colmenero J, Márquez M, Santos J, Grupo Malagueño para el Estudio de las Enfermedades Infecciosas. 2008. Prevalencia de mutaciones de resistencia primaria en los nuevos diagnósticos de infección por el VIH en la provincia de Málaga. Enferm Infect Microbiol Clin 26:141-145.

Palella FJ, Jr., Delaney KM, Moorman AC, Loveless MO, Fuhrer J, Satten GA, Aschman DJ, Holmberg SD. 1998. Declining morbidity and mortality among patients with advanced human immunodeficiency virus infection. HIV Outpatient Study Investigators. N Engl J Med 338:853-860.

Pernas B, Grandal M, Mena A, Castro-Iglesias A, Cañizares A, Wyles DL, López-Calvo S, Pértega S, Rodríguez-Osorio I, Pedreira JD, Poveda E. 2014. High prevalence of subtype F in newly diagnosed HIV-1 persons in northwest Spain and evidence for impaired treatment response. AIDS 28:1837-1840.

Phillips AN, Gazzard B, Gilson R, Easterbrook P, Johnson M, Walsh J, Leen C, Fisher M, Orkin C, Anderson J, Pillay D, Delpech V, Sabin C, Schwenk A, Dunn D, Gompels M, Hill T, Porter K, Babiker A, UK Collaborative HIV Cohort Study. 2007. Rate of AIDS diseases or death in HIV-infected antiretroviral therapy-naive individuals with high CD4 cell count. AIDS 21:1717-1721.

Recommendation from the GESIDA/Spanish AIDS Plan regarding antiretroviral treatment in adults with human immunodeficiency virus infection (update January 2007). Enferm Infecc Microbiol Clin 25:32-53.

Rodriguez-Rodrigues N, Duran A, Bouzas MB, Zapiola I, Vila M, Indyk D, Bissio E, Salomon H, Dilernia DA. 2013. Increasing trends in primary NNRTI resistance among newly HIV-1 diagnosed individuals in Buenos Aires, Argentina. J Int AIDS Soc 16:18519.

Sabin CA, Schwenk A, Johnson MA, Gazzard B, Fisher M, Walsh J, Orkin C, Hill T, Gilson R, Porter K, Easterbrook P, Delpech V, Bansi L, Leen C, Gompels M, Anderson J, Phillips AN, UK Collaborative HIV Cohort (UK CHIC) Steering Committee. 2010. Late diagnosis in the HAART era: Proposed common definitions and associations with mortality. AIDS 24:723-7727.

Sagir A, Oette M, Kaiser R, Däumer M, Fátkenheuer G, Rockstroh JK, Knechten H, Schmutz G, Hower M, Emmelkamp J, Pfister H, Häussinger F, RESINA Study Team. 2007. Trends in prevalence of primary HIV drug resistance in Germany. J Antimicrob Chemother 60:843-848.

Sax PE, Islam R, Walensky RP, Losina E, Weinstein MC, Goldie SJ, Sadownik SN, Freedberg KA. 2005. Resistance testing be performed for treatment-naive HIV-infected patients? A cost-effectiveness analysis. Clin Infect Dis 41:1316-1326.

Scherrer AU, Ledergerber B, von Wyl V, Böni J, Yerly S, Klimkait T, Bürgisser P, Rauch A, Hirschel B, Cavassini M, Elzy L, Vernazza PL, Bernasconi E, Held L, Günthard HF, Swiss HIV Cohort Study. 2011. Improved virological outcome in White patients infected with HIV-1 non-B subtypes compared to subtype B. Clin Infect Dis 53:1143-1152.

Scognamiglio P, Chiaradia G, De Carli G, Giuliani M, Mastroianni CM, Aviani Barbacci S, Buonomini AR, Grisetti S, Sampaolesi A, Corpolongo A, Orchi N, Puro V, Ippolito G, Girardi E, SENDIH Study Group. 2013. The potential impact of routine testing of individuals with HIV indicator diseases in order to prevent late HIV diagnosis. BMC Infect Dis 13:473.

Shen Y, Lu H, Wang Z, Qi T, Wang J. 2013. Analysis of the immunologic status of a newly diagnosed HIV positive population in China. BMC Infec Dis 13:429.

Thomson MM, Fernández-García A, Delgado E, Vega Y, Díez-Fuertes F, Sánchez-Martínez M. 2012. Rapid expansion of a HIV-1 subtype F cluster of recent origin among men who have sex with men in Galicia, Spain. J Acquir Immune Defic Syndr 59:e49-e51.

Treviño A, Soriano V, Rodríguez C, Arredondo M, Rivas P, Herrero-Mendoza D, Parra P, del Romero J, Anta L, Puente S, de Mendoza C. 2011. Changing rate of non-B subtypes and coinfection with hepatitis $\mathrm{B} / \mathrm{C}$ viruses in newly diagnosed HIV type 1 individuals in Spain. AIDS Res Hum Retroviruses 27:633638.

Van Griensven F, de Lind van Wijngaarden JW, Baral S, Grulich A. 2009. The global epidemic on HIV infection among men who have sex with men. Cur Opin HIV AIDS 4:300-307.

Vandamme AM, Sonnerborg A, Ait-Khaled M, Albert J, Asjo B, Bacheler L, Banhegyi D, Boucher C, BrunVézinet F, Camacho R, Clevenbergh P, Clumeck N, Dedes N, De Luca A, Doerr HW, Faudon JL, Gatti G, Gerstoft J, Hall WW, Hatzakis A, Hellmann N, Horban A, Lundgren JD, Kempf D, Miller M, Miller V, Myers TW, Nielsen C, Opravil M, Palmisano L, Perno CF, Phillips A, Pillay D, Pumarola T, Ruiz L, Salminen M, Schapiro J, Schmidt B, Schmit JC, Schuurman R, Shulse E, Soriano V, Staszewski S, Vella S, Youle M, Ziermann R, Perrin L. 2004. Updated European recommendations for the clinical use of HIV drug resistance testing. Antivir Ther 9:829-848. 
Walèria-Aleixo A, Martins AN, Arruda MB, Brindeiro RM, Da-Silva RM, Nobre FF, Greco DB, Tanuri A. 2008. Drug resistance mutation profile and accumulation kinetics in human immunodeficiency viruspositive individuals infected with subtypes $\mathrm{B}$ and $\mathrm{F}$ failing highly active antiretroviral therapy are influenced by different viral codon usage patterns. Antimicrob Agents Chemother 52:4497-4502.

WHO/UNAIDS. 2013. Global Report, UNAIDS report on the global AIDS epidemic 2013. WHO/UNAIDS. Available at http://www.unaids.org/en/media/unaids/contentassets/documents/epidemiology/2013/gr2013/UNAIDS_G lobal_Report_2013_en.pdf.

Wittkop L, Günthard HF, de Wolf F, Dunn D, Cozzi-Lepri A, de Luca A, Kücherer C, Obel N, von Wyl V, Masquelier B, Stephan C, Torti C, Antinori A, García F, Judd A, Porter K, Thièbaut R, Castro H, van Sighem AI, Colin C, Kjaer J, Lundgren JD, Paredes R, Pozniak A, Clotet B, Phillips A, Pillay D, Chêne G, EuroCoord-CHAIN study group. 2011. Effect of transmitted drug resistance on virological and immunological response to initial combination antiretroviral therapy for HIV (EuroCoord-CHAIN joint Project): A European multicohort study. Lancet Infect Dis 11:363-371.

Yirrell DL, Shaw L, Campbell E, Burns SM, Cameron SO, Goldberg D. 2008. HIV subtypes in Scotland, 2000-2006. Epidemiol Infect 136:1069-1075.

Zhang M, Foley B, Schultz AK, Macke JP, Bulla I, Stanke M, Morgenstern B, Korber B, Leitner T. 2010. The role of recombination in the emergence of a complex and dynamic HIV epidemic. Retrovirology $7: 25$. 